\title{
Genetic Structure of SSR1 \& SSR2 loci from Iranian Mycobacterium Avium Subspecies Paratuberculosis Isolates by a Short Sequence Repeat Analysis Hpproach
}

\author{
Aida Chalesh (MSc) \\ Razi Vaccine \& Serum Research Institute \\ (RVSRI), Karaj, and Islamic Azad University, \\ Rasht Branch, Rasht, Iran \\ Keyvan Tadayon (PhD) \\ Razi vaccine \& Serum Research Institute \\ (RVSRI), Karaj, Iran \\ Corresponding Author: Keyvan Tadayon \\ Email: k.tadayon@rvsri.ac.ir
}

\section{Tel:+989124968907}

Address: Razi vaccine \& Serum Research Institute (RVSRI), Karaj, Iran

Received: 04 Apr 2015

Revised: 07 May 2015

Accepted: 15 May 2015
ABSTRACT

Background and Objective: Paratuberculosis has been repeatedly reported from Iranian ruminant herds. The extrem fastidious nature of Mycobacterium avium subspecies paratuberculsos hinders genomic diversity studies of the pathogen. Short Sequence Repeat analysis is one of the genome-based approches recently developed to overcome this difficulty. In this study we describe the application of SSR genotyping on three Iranian MAP type strains plus the III \& V vaccinal strain.

Methods: All the bacteria were examined by PCR-F57 and PCR-IS900 experiments in order to authenticate their identity as MAP. SSR genotyping using SSR1 \& SSR2 loci was conducted according to the Amonsin method. PCR amplicons were sequenced to guarantee the accuracy of findings.

Results: At SSR1 locus two allels were identified, a larger allel of 770 bp and a smaller allel of 763 bp long. At SSR2 only a single allele, 800 bp long, was detected. Two Iranian bovine and ovine MAP isolates along with the vaccinal III \& V strain shared a single SSR1/SSR2 pattern while a different SSR1/SSR2 was represented by the third (caprine) Iranian NAP isolate.

Conclusion: While finding a shared SSR type between the two Iranian MAP isolates and the III \& V strain might represent a mutual ancestral background but this has to be assessed through further studies. Detection of two SSR genotypes between three Iranian type strains is likely a reflection of more MAP clones in Iran.

Keywords: Mycobacterium Avium Subspecies Paratuberculosis (MAP), SSR Genotyping, Genetic Marker, Genetic Locus. 


\section{INTRODUCTION}

Paratuberculosis is among few the serious diseases in ruminants farming where the zoonotic importance of the condition have been overwhelmed by its economic losses $(1,2)$ Reduced economic value due to progressive emaciation, premature culling, drop in milk yield and meat production plus trade and transport restrictions on infected animals are some of the major challenges caused by paratuberculosis in struck herds. Pathological, microbiological and molecular biology findings over the last century have represented that Mycobacterium avium subspecies paratuberculosis (MAP), the aetiological agent of paratuberculosis, is capable of infecting humans of all ages (3) but its involvement in development of disease in human hosts is still controversial (4, 5). While it was demonstrated that bovine tuberculosis (bovine $\mathrm{Tb}$ ) have been infecting native cattle population of Iran before importation of the foreign breeds (6), introduction of paratuberculosis in local cattle, sheep and goat herds is contributed to the animal importation policy (7). Numerous previous studies on paratuberculosis epidemiology (8) indicated that this disease is now circulating in almost all farming zones of the country including Eastern Azerbaijan (9), Razavi Khoarasan (10) Fars
(11), Isfahan
(12), Markazi
(13),

Mazandaran (14) and Khouzestan(15). Funding obstacles along with extensive engagements of the Iranian Veterinary Organization (IVO) with bovine $\mathrm{Tb}$ and brucellosis control programs have resulted in removal of paratuberculosis from the IVO's current action plans despite its large devastating impacts.
Laboratory culture of MAP is not an easy experiment since its culture medium is required to be Iron-supplemented with mycobactin $\mathbf{J}$ and incubated for as long as several months(16). Over the last two decades, two groups of molecular biology techniques have been used in genetic characterization and diversity studies of MAP. These can be classified into primary genotyping methods such as RFLP-IS900, PFGE and high resolution genotyping methods, so-called "subtyping" systems like Variable Number Tandem Repeat (VNTR) and Short Sequence Repeat (SSR) typing. In 2004 in an attempt to detect SSR loci, Amonsin screened the recently-released genome of MAP K10 $(17,18)$. Among the 11 reported loci by Amonsin, there were single (eg. G), dual (eg. GC) and triple (eg. GGT) nucleotide repeat unit structures that were found to be polymorphic within MAP isolates (17). These newly-found polymorphic loci were employed by Amonsin in his initiative method, known as SSR typing. This system was later used by many other researchers and is now established as one of the few standard genotyping methods in epidemiological studies of MAP. With introduction of MAP vaccinal and laboratory strains including the III \& V to Razi Vaccine \& Serum Research Institute (RVSRI) in 1960s, attempts have been made to isolate and archive these mycobacteria at this institute. Due to lack of published data regarding the genomic characterization of MAP in Iran, this study aimed to evaluate the application of SSR typing on the III\&V strain and a number of Iranian MAP field isolates. 


\section{MATERIAL AND METHODS}

Three field MAP bacteria including a single bovine (originally, from Zanjan) plus two caprine and ovine (both from Isfahan) isolates along with the MAP III \& V strain were incorporated in this study (Table 1). The field bacteria were obtained from lymph nodes of autopsied paratuberculoid animals in 2010-2011 which were previously genotyped by standard MAP VNTR typing system (19). Therefore, Razi 01450 (cattle), Razi 01911 (goat) and Razi 01231 (sheep) isolates representing INMV5, INMV39 and INMV2 VNTR types respectively, were selected to participate in this study. Besides, the MAP III \& V strain shared INMV2 type with the sheep isolate (19).

All the bacteria were sub-cultured on mycobactin J-supplemented Herrold's egg yolk medium and incubated at $37^{\circ} \mathrm{C}$ for $8-12$ weeks until colonies became visible. Mycobacterial growth characteristics were examined by acid-fast microscopy. Bacterial genome was extracted through the boiling method (20).

Two genomic markers of IS900 and F57 were employed in order to authenticate the identity of bacteria as MAP. Polymerase chain reaction (PCR) was conducted according to the method developed by Dohmann (21) , Schonenbrucher (22) and their following modifications by Ebrahim(23). SSR genotyping was performed as instructed by Amonsin(17). For financial reasons and cost management, two of the 11 SSR loci studied in the Amonsin study e.g. SSR1 and SSR2 with the highest level of genomic diversity were selected and used in this research. A new pair of primers was designed and used to amplify SSR2 due to difficulties caused by those from the original method of Amonsin.
About $1 \mathrm{~kb}$ of MAP K10 genome (available at ftp://ftp. ncbi.nlm.nih.gov/genomes/), surrounding the locus was selected and fed to the Primer 3 version 4.0.0 $(24,25)$ software to design the primers (Table 1).

PCR optimization was achieved through the recommended procedure by Najafi Olya(26). The $12 \mu$ l PCR reactions consisted of $6 \mu \mathrm{l}$ commercial PCR master $\operatorname{mix}$ (Ampliquor ${ }^{\circledR}$, Denmark). This ready to use cocktail holds all the PCR-required minerals and enzyme ingredients Including $1 \mu \mathrm{l}$ of each primer, $0.48 \mu \mathrm{l}$ DMSO, $3 \mu \mathrm{l}$ DNA template plus $0.52 \mu \mathrm{l}$ PCR water. Plain PCR water was used as negative control. Gel electrophoresis of PCR amplicons was performed using pre-stained molecular grade agarose gels $(1,5 \%)$ with Red safe $^{\circledR}$ (Invitrogen $^{\circledR}$, USA) for $2 \mathrm{~h}$ on a $2 \mathrm{~V} / \mathrm{cm}$ electrical field. This was followed by gel photography $\left(\mathrm{BioRad}^{\circledR}\right.$, USA) where a 100 bp DNA size marker (Invitrogen ${ }^{\circledR}$, USA) was incorporated to assist visual sizing of PCR products. Two PCR protocols were used in this study. The first protocol was applied in IS900 \& F57 experiments and included an initiation heating phase at $95^{\circ} \mathrm{C}$ for $5 \mathrm{~m}$ followed by 40 cycles of $95^{\circ} \mathrm{C}$ for $30 \mathrm{~s}, 61^{\circ} \mathrm{C}$ for $30 \mathrm{~s}$ and $72^{\circ} \mathrm{C}$ for $45 \mathrm{~s}$ plus a single ending extension phase of $72^{\circ} \mathrm{C}$ for $10 \mathrm{~m}$. The second protocol was used for SSR genotyping where PCR reactions were initially treated for $5 \mathrm{~m}$ at $95^{\circ} \mathrm{C}$ and then went under 35 cycles of $95^{\circ} \mathrm{C}$ for $1 \mathrm{~m}, 62^{\circ} \mathrm{C}$ for $45 \mathrm{~s}, 72^{\circ} \mathrm{C}$ for $45 \mathrm{~s}$ and a final extension step at $72^{\circ} \mathrm{C}$ for $10 \mathrm{~m}$.

\section{RESULTS}

All four tested bacteria produced a $560 \mathrm{bp}$ and a 704 bp long fragment in PCR-IS900 and PCR-F57 experiments, respectively, to 
prove their identity as MAP. Analysis of gel electrophoresis findings regarding the SSR1 and SSR2 loci (Figure 1) supported by sequencing results and paralleled by outcomes of running the tandem repeat finder package, detected a larger allele of 770 bp represented by MAP III \& V, Razi 01450 and Razi 01231 and a smaller allele of 763 bp produced by Razi 01911 at SSR1.
Moreover, at SSR2 a single unique allele of $800 \mathrm{bp}$ was shared by all tested bacteria. When the constructing repeats at SSR1 \& SSR2 loci were searched, it was understood that they both consisted of "G" units. At SSR1, there were 7 (allele 1) or 19 (allele 2) copies of "G" units, and at locus SSR2, there was 10 copies of this repeat unit in the study panel (Figure 2).

Table 1- Primers used for PCR amplification of MAP identification markers and SSR genotyping. Genomic characterizations of these are detailed based on MAP K10 genome.

\begin{tabular}{|c|c|c|c|c|c|c|}
\hline Locus/primer & Alias & Nucleotide sequence $\left(5^{\prime} \rightarrow 3^{\prime}\right)$ & Start & Stop & $\begin{array}{l}\text { Expected } \\
\text { size (bp) }\end{array}$ & Reference (s) \\
\hline IS900f & - & 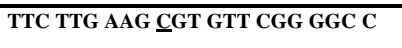 & 39815 & 39836 & 560 & (21) \\
\hline IS900r & & GCG ATG ATC GCA GCG TCT TTG G & 40353 & 40374 & & \\
\hline F57f & - & ACC GAA TGT TGT TGT CAC CG & 886774 & 886793 & 704 & $(22,23)$ \\
\hline F57r & & GGA CAC CGA AGC ACA CTC TC & 887458 & 887477 & & \\
\hline SSR1f & & ACC TTC ACC CCG AGT ACA AC & 1792754 & 1792773 & 770 & (17) \\
\hline SSR1r & & CGG CCT CAT AAC CGT TGC T & 1793505 & 1793523 & & \\
\hline SSR2f & & CCT CCA GCC CGG AAT CGT C & 2718626 & 2718644 & 800 & This Study \\
\hline SSR2r & & CTG TTC GCC GCC CAG C & 2719410 & 2719425 & & \\
\hline
\end{tabular}

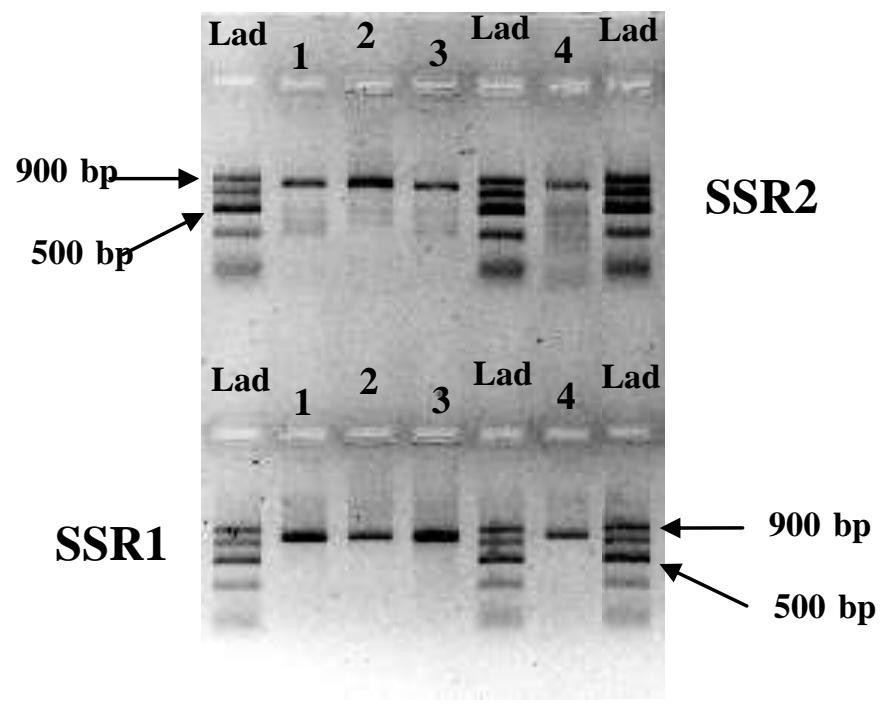

Figure 1- The amplification products of SSR1 \& SSR2 from Iranian MAP isolates: Razi 01911 (lane 1), Razi 01450 (lane 2),Razi 01231 (lane 3) and the laboratory strain of MAP III \& V (lane 4). The DNA size marker (marked as "Lad") has 5 bands depicting 900, 700, 500, 300 and 100 bp rungs. 
Figure 2- Clustal X (2.0.12) alignment of SSR1 (A) and SSR2 (B) loci in genomes of MAP K10 and three MAP isolates from Iran (Razi 01231, Razi 01450 and Razi 01911) plus the laboratory strain of MAP III \& V. The dots (.) indicate those sites where all the DNA sequences are homologous.

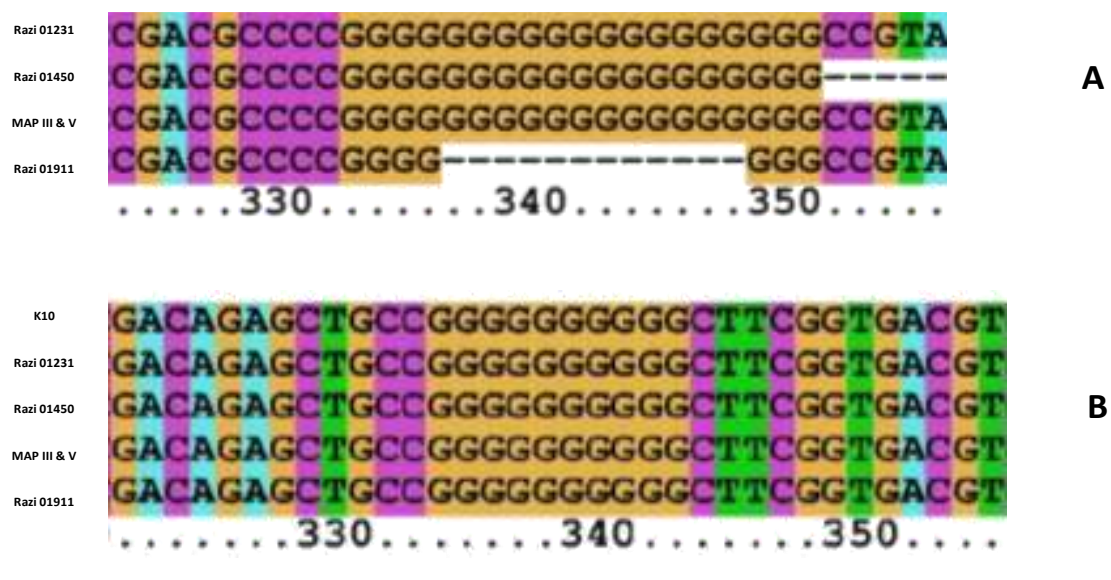

\section{DISCUSSION}

SSR1 and 2 loci with "G" unit repeats are genetically known to be highly polymorphic among the 11 loci introduced by Amonsin in MAP population(17). This observation was later noticed by others such as Sohal in Canada(27), Ricchi in Italy (28) and Okuni in Uganda where African MAP isolates were studied(29). Therefore selection and focus of this study on SSR1 and SSR2 loci are justified. While some SSR types demonstrate no host-specificity, there are cases where different hosts are struck by specific genotypes $(30,31)$. To exemplify, all studied human MAP isolates carry 7 copies of "G" units at their SSR1 locus (30). Due to lack of available data in Iran, authors of this study are unable to comment further; nevertheless we know that those MAP isolates holding 19 copies of the unit repeat have the capability to infect both cattle and goats in the Iranian environment. The MAP K10 is a wellknown bovine laboratory strain with a fully-characterized genome, available to public domain (32) Comparative structure analysis of SSR1 and SSR2 loci showed that the MAP III \& V strain, the Iranian bovine and ovine isolates similar to the well-known MAP K10 strain carry 19 and 10 copies of the unit repeat at these loci, respectively. This specific type therefore, benefits from a broader geographical frequency compared to other types reported from the US(27), Canada (27) and Europe (28) .Contrary to bovine $\mathrm{Tb}$, no documented evidence on paratuberculosis activity in Iranian ruminants is available before importation of pure-breed animals initiated. Besides, some Iranian workers have blamed imported animals from the UK and Israel for transboundary introduction of the infection into Iran. Assuming that an identical SSR1 \& SSR2 genomic structure is shared between two Iranian MAP isolates and the exotic strains of, MAP III \& V and MAP $\mathrm{K} 10$, cannot ascertain a mutual origin and phylogeny on its own between these, as only two loci have been studied. On the other hand, circulation of at least two SSR types in Iranian farms, as demonstrated in this study, indicates that some level of genomic diversity is present in the MAP population in Iran. Further research is however necessary using extra SSR loci and MAP isolates to address the origin and phylogeny of paratuberculosis in Iran. 


\section{CONCLUSION}

While shared SSR1 and SSR2 types between bovine and ovine hosts of MAP in Iran might reflect an associated epidemiology but this assumption needs to be analyzed through future studies. Detection of two MAP strains between Iranian field isolates is possibly referring to more clones than the currently circulating clones in this environment.

\section{ACKNOWLEDGEMENTS}

The authors would like to thank the Razi Vaccine \& Serum Research Institute (RVSRI) for financial assistance under research grant number 2.18.18.94106. We are indebted to Dr N. Mosavari and Dr A.A.

\section{References}

1. Wolf R, Clement F, Barkema HW, Orsel K. Economic evaluation of participation in a voluntary Johne's disease prevention and control program from a farmer's perspective--The Alberta Johne's Disease Initiative. J Dairy Sci. 2014; 97(5): 2822-34.

2.Nagel-Alne GE, Asheim LJ, Hardaker JB, Solverod L, Lindheim D, Valle PS. The Norwegian Healthier Goats programme--a financial cost-benefit analysis. Prev Vet Med. 2014; 114(2): 96-105.

3.Wynne JW, Beller C, Boyd V, Francis B, Gwozdz J, Carajias $\mathrm{M}$, et al. SNP genotyping of animal and human derived isolates of Mycobacterium avium subsp. paratuberculosis. Vet Microbiol. 2014; 172(3-4): 479-85.

4.Nacy C, Buckley M. Mycobacterium avium paratuberculosis: infrequent human pathogen or public health threat. ASM Academy. 2008; 1-37.

5.Ronai Z, Csivincsik A, Gyuranecz M, Kreizinger Z, Dan A, Janosi S. Molecular analysis and MIRU-VNTR typing of Mycobacterium avium subsp. paratuberculosis strains from various sources. J Appl Microbiol. 2015; 118(2): 275-83.

6.Tadayon K, Mosavari N, Feizabadi MM. An epidemiological perspective on bovine tuberculosis spotlighting facts and dilemmas in Iran, a historically zebudominant farming country. Iran J Microbiol. 2013; 5(1): 113.

7.Baharsefat M, Amjadi A, Ahourai P, Yamini B, Entessar F, Hedayati H. Maladie de Johne (Paratuberculose) chez les Caprins et les Ovins en Iran. Arch Inst Razi. 1972; 24(13): 49-61.

8.Talatchian M. First report of Johne's disease in Iran. Bull Off Int Epizoot. 1965; 64(779-82.

9.Fathi R, Sarkarati F, Eslami M, Rezavand B, Nourizadeh A. Paper: Detection of Mycobacterium avium subspecies
Shahmoradi both from RVSRI, for providing the MAP III \& V strain as well as sheep and goat paratuberculosis specimens from Isfahan. Dr R. Keshavarz, M. Sekhavati and Sh. Dashtipour are gratefully appreciated for conducting the bacterial isolation, sub-culture and DNA extraction. Miss M. M. Haghighat and Mrs N. Karimnasab are acknowledged for help with PCRs and sequencing. Aida Chalesh is a former MSc student recently graduated from Islamic Azad University of Rasht.

\section{CONFLICT OF INTEREST}

The authors declare no conflict of interest between them. paratuberculosis in Cow Milk Using Culture and PCR Methods. Archives of Razi Institute. 2011; 66(2): 6.

10.Seyyedin M, Zahraeai T, Fathi Najafi M. Comparison of Isolation Frequency of Mycobacterium avium subspecies paratuberculosis from Different Types of Samples. Pakistan Veterinary Journal. 2010; 30(3): 143-149.

11.Ansari-Lari M, Haghkhah M, Bahramy A, Novin Baheran AM. Risk factors for Mycobacterium avium subspecies paratuberculosis in Fars province (Southern Iran) dairy herds. Trop Anim Health Prod. 2009; 41(4): 553-7.

12.Shahmoradi AH, Arefpajohi R, Tadayon K, Mosavari N. Paratuberculosis in Holstein-Friesian cattle farms in Central Iran. Trop Anim Health Prod. 2008. 40(3): 169-73.

13.Ghaem Maghami S, Khosravi M, Ahmadi M, Denikoo A, Haghdin M, Koochakzadeh A. Study of the Prevalence Rate of John's Disease in Markazi Province and Evaluation of Absorbed ELISA for Adoption as a Dignostic Method. Scientific Research Iranian Veterinary Journnal. 2012; 8(3): 54-59.[Persian]

14.Sadati R, Jafarpour M, Mirinargesi M, Nazemi A, Barghi A. Prevalence of Mycobacterium avium subsp. paratuberculosis in dairy cattle bred in northern Iran by nested PCR. Global Vet. 2012; 8(3): 259-263.

15.Hajikolaei M, Ghorbanpoor M, Solaymani M. The prevalence of Mycobacterium paratuberculosis infection in ileocaecal valve of cattle slaughtered in Ahvaz abattoir, southern Iran. Iranian Journal of Veterinary Research. 2006; 7(2): 77-80.

16.Dimareli-Malli Z, Mazaraki K, Stevenson K, Tsakos P, Zdragas A, Giantzi V, et al. Culture phenotypes and molecular characterization of Mycobacterium avium subsp. 
paratuberculosis isolates from small ruminants. Res Vet Sci. 2013; 95(1): 49-53.

17.Amonsin A, Li LL, Zhang Q, Bannantine JP, Motiwala AS, Sreevatsan S, et al. Multilocus short sequence repeat sequencing approach for differentiating among Mycobacterium avium subsp. paratuberculosis strains. J Clin Microbiol. 2004. 42(4): 1694-702.

18. Wynne JW, Seemann T, Bulach DM, Coutts SA, Talaat AM, Michalski WP. Resequencing the Mycobacterium avium subsp. paratuberculosis K10 genome: improved annotation and revised genome sequence. $\mathrm{J}$ Bacteriol. 2010; 192(23): 6319-20.

19.Thibault VC, Grayon M, Boschiroli ML, Hubbans C, Overduin P, Stevenson K, et al. New variable-number tandem-repeat markers for typing Mycobacterium avium subsp. paratuberculosis and M. avium strains: comparison with IS900 and IS1245 restriction fragment length polymorphism typing. J Clin Microbiol. 2007; 45(8): 240410.

20.Ahmadi M, Tadayon K, Mosavari N, Farazi A, Arjmanzadegan M, Keshavarz $\mathrm{P}$, et al. Mycobacterium tuberculosis genotyping by MIRU-VNTR method. Journal of Gorgan University of Medical Sciences. 2014; 17(1): 97 107.[Persian]

21.Dohmann K, Strommenger B, Stevenson K, de Juan L, Stratmann J, Kapur V, et al. Characterization of genetic differences between Mycobacterium avium subsp. paratuberculosis type I and type II isolates. J Clin Microbiol. 2003. 41(11): 5215-23.

22.Schonenbrucher H, Abdulmawjood A, Failing K, Bulte M. New triplex real-time PCR assay for detection of Mycobacterium avium subsp. paratuberculosis in bovine feces. Appl Environ Microbiol. 2008; 74(9): 2751-8.

23.Ebrahim Z, Tadayon K, Mosavari N. Genomic Characterization of the Vaccinal Strain of Mycobacterium avium subspecies paratuberclosis (MAP) $316 \mathrm{~F}$ by MIRUVNTR. Medical Laboratory Journal. 2015. 9(3): p.

24.Ye J, Coulouris G, Zaretskaya I, Cutcutache I, Rozen S, Madden TL. Primer-BLAST: a tool to design target- specific primers for polymerase chain reaction. BMC Bioinformatics. 2012; 13: 134.

25.Untergasser A, Cutcutache I, Koressaar T, Ye J, Faircloth BC, Remm M, et al. Primer3--new capabilities and interfaces. Nucleic Acids Res. 2012. 40(15): e115.

26.Najafi Olya Z, Tadayon K, Ghaderi R. A Simplified Van Erth Single Nucleotide Polymorphism (SNP) Typing Method of Bacillus Anthracis Applicable by Traditional Thermocycler Machines. mljgoums. 2015; 9 (1): 97-103.

27.Sohal JS, Arsenault J, Labrecque O, Fairbrother JH, Roy JP, Fecteau G, et al. Genetic structure of Mycobacterium avium subsp. paratuberculosis population in cattle herds in Quebec as revealed by using a combination of multilocus genomic analyses. J Clin Microbiol. 2014; 52(8): 2764-75.

28.Ricchi M, Barbieri G, Taddei R, Belletti GL, Carra E, Cammi G, et al. Effectiveness of combination of Mini-and Microsatellite loci to sub-type Mycobacterium avium subsp. paratuberculosis Italian type C isolates. BMC Vet Res. 2011; 7: 54. doi:10.1186/1746-6148-7-54.

29.Okuni JB, Dovas CI, Loukopoulos P, Bouzalas IG, Kateete DP, Joloba ML, et al. Isolation of Mycobacterium avium subspecies paratuberculosis from Ugandan cattle and strain differentiation using optimised DNA typing techniques. BMC Vet Res. 2012; 8: 99.

30.Ghadiali AH, Strother M, Naser SA, Manning EJ, Sreevatsan S. Mycobacterium avium subsp. paratuberculosis strains isolated from Crohn's disease patients and animal species exhibit similar polymorphic locus patterns. J Clin Microbiol. 2004; 42(11): 5345-8.

31.Motiwala AS, Strother M, Amonsin A, Byrum B, Naser SA, Stabel JR, et al. Molecular epidemiology of Mycobacterium avium subsp. paratuberculosis: evidence for limited strain diversity, strain sharing, and identification of unique targets for diagnosis. J Clin Microbiol. 2003; 41(5): 2015-26.

32.Li L, Bannantine JP, Zhang Q, Amonsin A, May BJ, Alt $\mathrm{D}$, et al. The complete genome sequence of Mycobacterium avium subspecies paratuberculosis. Proc Natl Acad Sci U S A. 2005; 102(35): 12344-9. 